\title{
The Classification of Heritage Tourists: A Case of Hue City, Vietnam
}

\author{
Thi Hong Hai Nguyen \& Catherine Cheung
}

\section{Introduction}

Heritage tourism is currently one of the most notable and widespread types of tourism in terms of visitors and attractions, appealing to hundreds of millions of people every year (Timothy, 2011). The World Tourism Organization (UNWTO) claims that almost 40 per cent of all international trips undertaken are related to heritage and culture and the demand for both is growing at 15\% per annum (Boyd, 2001; McKercher, 2002). This trend is expected to grow continuously given the recent movement to 'grey' tourism within Western and European markets and the increasing interest in culture within the tourism sector (Ashworth, 2004; Boyd, 2001). With the introduction of the World Heritage List in the late $20^{\text {th }}$ century, both the demand and supply sides of heritage tourism have received increasing attention and subsequent growth. Indeed, a heritage or world heritage status is becoming a significant selling point for tourism destinations (Timothy \& Boyd, 2003).

Heritage tourism is also the main tourism product and attractiveness of the city of Hue, the capital city of Thua Thien Hue Province. Located in central Vietnam, Hue is known as one of the most famous heritage destinations in the country. Being the last feudal capital of Vietnam, Hue still retains plenty of historical and cultural vestiges. Arguably, the two most famous cultural/heritage products are the Complex of Hue monuments and the Vietnamese Court Music. Indeed, the various cultural and heritage attractions, beautiful beaches, landscape and appealing culture have given Hue the status of a popular tourism destination. The local tourism industry has been developed since the 90s, especially after the Complex of Hue monuments has being listed as World Cultural Heritage in 1993. From eight thousands arrivals in 1990, the city has welcomed 1.5 million visitors in 2010 and generated USD\$67million of related revenue (Hue People's Committee, 2012).

In spite of the fact that heritage tourism is the predominant type in Hue, up to date there are hardly any official statistics and a lack of related research persist. The number of visitors to heritage sites and the revenue of heritage tourism are usually counted by the amount of tickets sold in six heritage sites under the management of the Hue Monuments Conservation Centre. These numbers show a stable increase in both, visitors and revenue (Hue Monuments Conservation Center, 2010). However, there is no available information about the characteristics of the heritage tourists and heritage tourism itself. Important concerns, such as how important heritage is for the tourists' choice of visiting Hue, who the related heritage tourists are, what activities they choose, and what sites they visit remain unclear.

The knowledge gaps exist in Hue heritage tourism and tourists should be narrowed. It is because understanding tourists and their behavior is believed to be of vital importance for tourism management bodies. Within the field of heritage tourism, scholars attempted to investigate heritage tourist profiles as well as categorizing them into different groups for a better understanding of heritage tourists and their experiences (McKercher, 2002; Garrod \& Fyall, 2001; Prentice, 1993; Silberberg, 1995; Stebbin, 1996). This study aims at providing a preliminary profile of heritage tourists to Hue city, focusing on the classification of heritage 
tourists. The data of this study is derived from a larger research* that examined heritage tourists visiting Hue city in package tours. Subsequently, a set of secondary data on heritage tourists travelling in package tours are reported. The specific objectives of the paper are (1) to build a profile of Hue heritage tourists in package tours; (2) to classify Hue heritage tourists in package tours and to identify characteristics of these different groups; and ultimately (3) to discuss possible managerial implications.

\section{Literature review}

\section{Cultural and heritage tourists' classification}

Heritage tourism is considered as one of the oldest forms of tourism, dating back to ancient records of explorers, sailors and traders (Timothy \& Boyd, 2003). The definition of heritage tourism, nevertheless, is complex and still widely disputed. In general, definitions fall into two perspectives, i.e. from the demand or supply-side (Garrod \& Fyall, 2000; Poria, Butler \& Airey, 2003; Timothy \& Boyd, 2003; Yale, 1991). The World Tourism Organization defines heritage tourism as "an immersion in the natural history, human heritage, arts, philosophy and institutions of another region or country" (as cited in Timothy \& Boyd, 2003, p.1). Swarbrooke (1994) includes both supply and demand sides, defining heritage tourism as a type of travel where heritage is the core product and heritage is the main visitor motivation. In the present study, heritage tourism refers to activities of visiting or experiencing heritage, taking into account its natural, cultural and urban types.

Related to the previous discussed issues in definition, the question of who is a heritage tourist also appears to be a controversial topic. A heritage or cultural tourists have long been assumed to be virtually anyone who visits a cultural heritage property (Garrod \& Fyall, 2001). Arguments and debates about whether or not this can be considered true are still ongoing (Timothy, 2007). Nevertheless, a predominant part of recent scholars seems to accept cultural/heritage tourists as anyone who visits a cultural/heritage attraction. Subsequently, the research focus has shifted to identifying different types of heritage tourists.

Literature generally grouped tourists based on the predictors of expressed tourist behavior, such as why tourists choose a certain place, and what the experiences from the visits are (Isaac, 2008). Both practitioners and academics consider tourist classification as an effective way to bring about deeper understanding of tourists and to explain, or even predict their behavior (Isaac, 2008). Various scholars have shown that different groups of cultural/heritage tourists have indeed diverse motivations, behaviors and seek dissimilar experiences (McKercher, 2002; Prentice, 1993). Therefore, it is deemed as vital to identify and understand heritage tourists' typologies, their motives, behaviors, perceptions and experiences in order to deal efficiently with visitor management plans and marketing strategies.

Silberberg (1995) identifies four types of cultural tourists by an ascending level of interest in visiting cultural heritage sites: accidental cultural tourists, adjunct cultural tourists, in part cultural tourists and greatly cultural tourists. Accidental cultural tourists include people travelling without planning or intention to go to a cultural attraction, ending up taking the cultural opportunities accidentally. Adjunct cultural tourists are people for whom culture is an 'adjunct' motivation. People who

\footnotetext{
*Author's Master Thesis
} 
travel for both, cultural opportunities and additional reasons are considered in part cultural tourists. Ultimately, people who travel specifically because of opportunities to enjoy theatre, museums and cultural festivals and are greatly motivated by culture are called greatly cultural tourists.

In a research on heritage tourism in the United States, Shifflet and Associates (1999) categorize Pennsylvania heritage tourists based on the importance of heritage tourism in their choices of visits. Using a seven-point-scale of importance, three levels of heritage tourists were identified. In the following order of, core heritage travelers are those who represent the most dedicated heritage traveler group. Moderate heritage travelers represent the next most viable traveler group, which might have come for other reasons but still consider heritage tourism as an important factor in their decision of visit. At last, low heritage travelers are those who come for other reasons and most closely resemble non heritage tourists (Shifflet et al., 1999). This categorization provides useful information in particular for heritage marketing and management in Pennsylvania, by considering for instance the impact of heritage tourists on the destination.

The ICOMOS and WTO (1993) categorize visitors to heritage sites for the purpose of interpretation and education. Four types of heritage visitors were identified: (1) scholar visitors are those who are well-prepared and familiar with the history of the sites; (2) general visitors come to heritage sites because they have heard or read little about the sites but still don't have much related knowledge; (3) students are a possible group of frequent visitors and (4) another segment of visitors are brought to the sites as a part of a package tour are reluctant visitors. The latter have no or little information about the sites. Features of these visitor types and management strategies were also proposed. For scholar visitors, for instance, the primary objective should be to make their visits as pleasant, easy and informative as possible. General visitors instead seek for common understanding of international, national and local historical significance of the sites. The reluctant visitors are usually more interested in tourist amenities than in heritage knowledge.

When proposing a definition for heritage tourism, Poria, Butler and Airey (2001, p.1048) suggest three types of heritage tourists: (1) "those visiting what they consider as a heritage site though it is unconnected with their own heritage"; (2) "those visiting a place they deem to be part of their heritage, even though it may not be categorized as a heritage site"; and (3) "those visiting a site specifically classified as a heritage place although being unaware of this designation".

Since heritage tourism and cultural tourism are interrelated and have many similarities, cultural tourist classifications would be worth considering. The above typologies are based on the significance of heritage in the choice of places only. Considering another perspective of the level of engagement with the attraction, Stebbin (1996) identifies two different types of hobbyist cultural tourists. Those who are generalized cultural tourists visit a variety of different sites and regions to get a wide, general knowledge of different cultures. Specialized cultural tourists, who focus on and revisit certain sites or cultural entities, are able to acquire a deeper and specific knowledge.

McKercher (2002) utilizes two dimensions in order to segment the cultural tourism market. These two dimensions are (1) the importance of cultural motives in tourists' decisions to visit a destination and (2) the depth of information or level of 
engagement with the attraction (McKercher, 2002). Similar to other previously mentioned researchers, McKercher also observes that cultural tourism could be the main reason of visiting a destination for some tourists. For others, however, it plays a less important role or no role in their choices. In addition, the level of engagement with cultural and heritage attractions should also be taken into consideration when studying cultural tourists. According to McKercher (2002), the level of engagement is based on numerous factors such as educational level, awareness of the site before the visit, preconceptions of the site, interest, meaning to tourists, time availability and the presence of competing activities. For example, an independent tourist who spends several hours at a cultural site is different from a coach-trip tourist who has only a few minutes at the site, in terms of experience, demand and behavior. Considering these differences, the diverse types of visitors are believed to need different attentions from the supply side.

Based on those two dimensions, McKercher (2002) proposes a model which divides cultural tourists into five different types: (1) purposeful cultural tourists are those who have a deep cultural experience and their major reason of visit is learning about culture or heritage; (2) sightseeing cultural tourists visit mainly for culture or heritage. However, their experience is more shallow and entertainment-orientated; (3) casual cultural tourists are those whose cultural reason plays a limited role in the decision of the visit and subsequently they visit in a shallow manner; (4) incidental cultural tourists participate in cultural tourism activities, although cultural tourism plays little or no meaningful role in their destination decision-making process. They also have shallow experiences; (5) serendipitous cultural tourists visit cultural attractions and have a deep experience even if at the beginning cultural tourism plays little or no role in the decision to visit a destination. McKercher's (2002) model was successfully tested in the context of Hong Kong. The results demonstrate that different segments show indeed different behaviors at a destination, even though their demographic and trip profile patterns are similar.

This study considers heritage tourists as anyone who visits a heritage site and classifies them into different groups. After reviewing all of the above categorizations of cultural and heritage tourists, the cultural tourists' classification by McKercher (2002) was adopted for this study. While other scholars mostly use one dimension only in order to classify cultural or heritage tourists, McKercher employs two dimensions. Subsequently, his categorization is able to address tourists' behaviors in two travel stages of before and during the visit. This categorization of five types of tourists is believed to be the most comprehensive one.

Table 1. Summary of major categorizations of cultural and heritage tourists

\begin{tabular}{lll}
\hline \multicolumn{1}{c}{ Author(s) (year) } & \multicolumn{1}{c}{ Criteria } & \multicolumn{1}{c}{ Tourist categories } \\
\hline \multirow{2}{*}{$\begin{array}{l}\text { ICOMOS and WTO } \\
\text { (1993) }\end{array}$} & $\begin{array}{l}\text { Prior knowledge, } \\
\text { experience and } \\
\text { information they seek for }\end{array}$ & $\begin{array}{l}\text { - Scholar visitor } \\
\text { - General visitor } \\
\text { Silberberg (1995) }\end{array}$ \\
& $\begin{array}{l}\text { The level of interest in } \\
\text { visiting cultural heritage } \\
\text { sites }\end{array}$ & $\begin{array}{l}\text { - Accidental cultural tourist } \\
\text { - Adjunct cultural tourist } \\
\end{array}$ \\
\hline
\end{tabular}


This is a post-referred version of the paper published in Journal of Heritage Tourism, 9:1, 35-50, DOI:10.1080/1743873X.2013.818677

\begin{tabular}{|c|c|c|}
\hline Stebbin (1996) & $\begin{array}{l}\text { General/deep knowledge } \\
\text { of the visited site }\end{array}$ & $\begin{array}{l}\text { - Generalized cultural tourist } \\
\text { - Specialized cultural tourist }\end{array}$ \\
\hline $\begin{array}{l}\text { Shifflet and } \\
\text { Associates (1999) }\end{array}$ & $\begin{array}{l}\text { The importance of } \\
\text { heritage tourism in their } \\
\text { choice of visit }\end{array}$ & $\begin{array}{l}\text { - Core heritage traveler } \\
\text { - Moderate heritage traveler } \\
\text { - Low heritage traveler }\end{array}$ \\
\hline Poria et al. (2001) & $\begin{array}{l}\text { Official categorization/ } \\
\text { Personal perspective } \\
\text { towards heritage site }\end{array}$ & $\begin{array}{l}\text { - Considered as heritage } \\
\text { site/unconnected } \\
\text { - Not categorized as a heritage } \\
\text { site/their own heritage } \\
\text { - Classified as a heritage } \\
\text { site/unaware }\end{array}$ \\
\hline McKercher (2002) & $\begin{array}{l}\text { The importance of cultural } \\
\text { motives \& } \\
\text { The depth of information }\end{array}$ & $\begin{array}{l}\text { - Purposeful cultural tourist } \\
\text { - Sightseeing cultural tourist } \\
\text { - Casual cultural tourist } \\
\text { - Incidental cultural tourist } \\
\text { - Serendipitous cultural tourist }\end{array}$ \\
\hline
\end{tabular}

Together with the efforts to classify heritage tourists, a profusion of studies has investigated the characteristics of heritage tourists. This is of major importance, because tourists' characteristics, including demographics, socioeconomics, and travel behavior have always been essential within the field of tourism studies. Most previous studies of heritage tourists' characteristics show that they are younger or middle aged, likely to have a good education level, not only have professional and managerial jobs but also have a high average annual income, and they also tend to spend more than general tourists (Huh, Uysal, \& McCleary, 2006; Kerstetter, Confer, \& Graefe, 2001; Richards, 1996, 2001; Silberberg, 1995; Timothy, 2011). Even though, these features could be slightly different between places and heritage tourist types; for examples, heritage tourists in the USA are likely to be older or serious heritage tourists tend to be best educated (Timothy, 2011). In addition, heritage tourists are claimed to stay longer and spend more time on holiday than other types of tourists (Kerstetter et al., 2001; Silberberg, 1995; Timothy, 2011). According to Ashworth (2004), however, the length of stay at heritage destinations is believed to be much shorter than at others, such as for example beach resorts. Heritage tourism products are also argued to be rapidly consumed and tourists seldom stay for more than 2 days even at the world's most renowned cultural heritage centers such as Florence or Venice (Ashworth 2004). Van der Borg, Costa and Gotti (1996) also indicated that tourists spend on an average of 2 nights only in European heritage cities. These contradicting opinions can be explained by the fact that while Kerstetter et al. (2001), Silberberg (1995) and Timothy (2011) drawn their conclusions by using American and Canadian tourists, the studies of Ashworth (2004) and van der Borg et al. (1996) were held in a European context. It is therefore assumed that differences between these two markets can lead to opposite results. For this reason, the investigation of heritage tourists in an Asian context is an essential addition to the cultural and heritage literature.

\section{Heritage tourism in Hue city}


The tourism industry in Vietnam has started during the 60's of the last century. During that time, however, tourism was only meant for government-guests and other special invites, mainly taking place in the North of Vietnam. After the war, starting at 1975, Vietnam's tourism began to develop slowly. The industry, however, has only really grown and started to play an important role in the economy since the 1990's (VNAT, 2012). From then on, the tourism industry has achieved remarkable results and shown an impressive growth. The tourism revenue has reached VND $\$ 130$ thousands billions (about USD\$6 billion) in 2011 (VNAT, 2012). In the same year, visitor arrivals for the Vietnamese tourism industry reached 30 millions for domestic market and more than 6 millions for international market (VNAT, 2012).

Hue, the capital of Thua Thien Hue Province, is located in the central region of Vietnam, taking the place as one of the country's most interesting tourism centers. The city has a long history spanning from the formation of Thuan Hoa (1306) to the founding of Phu Xuan (1687), continuing up to the last feudal dynasty of Vietnam (1945) (Thua Thien Hue Portal, 2012). Hue has successfully maintained valuable cultural heritage, which according to local beliefs is symbolizing the Vietnamese intelligence and spirit (Thua Thien Hue Portal, 2012).

In the province of Thua Thien Hue, since the 1990's, the tourism industry has been developing gradually. Official tourism statistics show that the number of tourists has increased from one hundred thousand in 1990 to almost one and a half million in 2010 (Hue People's Committee, 2012). The revenue from VND\$11 billion in 1990 has reached VND\$1,400 billion (about USD $\$ 67$ million) in 2010 (Hue People's Committee, 2012; Hue Tourism Office, 2010). In the last ten years, the number of tourist arrivals has increased gradually with a significant growth rate of about 15 to 20 percent (Hue Tourism Office, 2010). However, in contrast to the steady growth rate, the tourists' length of stay was still relatively short, recorded around 2 days since the 90's. Interestingly, there is no big difference in numbers between the length of stay of international and domestic tourists.

Nowadays, Hue is well-known among domestic as well as international tourists for its cultural heritage. Examples therefore are world tangible and intangible cultural heritage, historical and revolutionary sites, religious relics, traditional festivals, traditional garden houses, and old towns. The two most famous heritage assets of the destination are the complex of Hue monuments which is inscribed in the UNESCO List of the World Cultural Heritage since 1993 and Nha Nhac, the Vietnamese Court Music which is recognized as a Masterpiece of the Oral and Intangible Cultural Heritage of Humanity by UNESCO since 2003 (Hue Monuments Conservation Centre, 2012). Among the complex of Hue monuments, the Imperial City of the Nguyen monarchical dynasties and some of the Royal Tombs to the west of the Hue Citadel are the most popular heritage sites. Also, the Hue Royal houses, or garden houses, are well-known because of their unique architecture. The royal times have also given birth to a unique cuisine and traditional food. In addition, the strong connection to Confucianism and Buddhism has led the city to build hundreds of Buddhist pagodas, temples and to celebrate various traditional festivals.

The number of visitors to heritage sites is usually counted by the amount of tickets sold in six heritage sites under the management of the Hue Monuments Conservation Centre. The mentioned sites are the Imperial City, Tu Duc Tomb, Khai Dinh Tomb, Minh Mang Tomb, Museum of Royal Antiquities and Hon Chen Temple. 
The total number of visitors to these sites has increased gradually and has reached 1.8 million in 2009 (Hue Monuments Conservation Centre, 2010). While the number of international tourists dropped in 2009 , domestic tourists still increased by $18 \%$. In the three year period from 2008 to 2010, the local heritage sites earned around VND $\$ 80$ billion a year, being equivalent to USD $\$ 4.23$ million (Hue Monuments Conservation Centre, 2010).

Besides the six ticketed sites, other most visited and famous out-door (ticket free) heritage sites are Kim Long - the Phu Mong garden houses, the Thien Mu Pagoda, the Thanh Toan Tile-proof Bridge, handicraft villages such as the Phuoc Tich ancient pottery village and the bronze casting guild.

In the efforts of developing tourism with particular attention to heritage, Hue city participated in The World Heritage Road, which spans through central Vietnam and is also the name of a project to develop and promote the area. This joint initiative from the three central Vietnamese provinces of Thua Thien Hue, Da Nang City, Quang Nam and the Vietnam National Administration of Tourism, strengthen the promotion and development of heritage tourism in Hue and the whole region. Furthermore, the Hue Festival and Traditional Handicrafts Festival are held every two years with the purpose of promoting culture, arts and tourism. This has been recognized as an opportunity to promote Hue as well as its cultural heritage locally and internationally.

\section{Methodology}

This study mainly employs a quantitative approach to build a profile of and to classify the heritage tourists to Hue city. A questionnaire was devised with closeended questions in order to obtain three sets of information. The first set collected information about the tourists' socio-demographic characteristics such as age, gender, level of education, occupation, and annual income. The second set aimed at obtaining information about the visit to Hue as being part of a tour, and the tourists' travel behaviours such as previous visits, reasons for travel, package vacation types, perceptions of the destination, activities they participated in, sites they visited in other destinations on the trip, and their willingness to stay longer or to revisit Hue. The third set of information included two dimensions proposed in the model of classification of the cultural tourists by McKercher (2002) which was adopted for categorizing cultural heritage tourists for this study.

All questions were organized into chronological order: before the visit, during the visit and future visit intentions, as well as from general to particular: information about the whole trip in Vietnam, information about the trip in Hue and personal information.

The questionnaires were sent to academic experts and practitioners for comments and suggestions. The pilot survey was conducted to ten tourists for validation. Interviewers were required to take notes on information such as understanding and sequential order of questions, variability in the answers provided, and the time needed to answer them. The questionnaire was then finalized and presented in three versions: English, French, and Vietnamese. The reason for including a French version was due to the French colonial history of Vietnam; France has always been an important international inbound market for Vietnam. Particularly in Hue, the French market was the biggest in 2009 (17.6\%) and second biggest in 2010 (16.7\%) among international tourists (Hue Tourism Office, 2011). 
Besides, French is the second most popular foreign language in the tourism industry as well as in the education system of Vietnam.

The survey was conducted during August and September 2010. The on-site survey with 300 questionnaires was carried out by staff and students from the Faculty of Hospitality and Tourism, Hue University. The survey was conducted at seven heritage sites in Hue city. A non-probability sampling technique was applied; meaning the convenience or availability samples, being fortuitously available for study, were approached. This type of sampling is commonly used for visitor surveys since respondents are available to be surveyed at a given period of time and space (Finn, Elliott-White, \& Walton, 2000). Tourists who were observed to be in package tours were approached during their free time and asked for participation in the survey. Tourists either filled the questionnaires on site, or completed that afterwards and questionnaires were then collected by student helpers at their hotels. . Around 150 questionnaires were also delivered to hotels; permissions were obtained from hotel managers to distribute the questionnaires by the front office receptionists. Package tourists were approached by front office receptionists to ask to fill in and return the questionnaires at their conveniences. Small gifts of appreciation were offered to increase the survey's response rate. Finally, a total of 307 complete questionnaires were obtained and usable, with a response rate of $68.2 \%$.

The Statistical Package for Social Sciences (SPSS) was utilized to analyze the data collected from the survey. Descriptive statistics, $t$ tests, and analysis of variance (ANOVA) were used as predominant tools.

Regarding the classification of heritage tourists adopting McKercher's (2002) model, two questions were included: (1) a five-point Likert scaled question for the centrality of heritage tourism in the tourists' decision to visit Hue, with answers ranking from 1 'Not important at all/did not influence' to 5 'Very important/main reason to visit Hue'; and (2) a four-point scaled question for the depth of the tourists' experience in Hue, with answers from 1 'mostly sightseeing/ photography or seeing interesting and famous sites' to 4 'a chance to develop a deep understanding of Hue Cultural Heritage'. The categories of heritage tourists were identified as: Purposeful heritage tourists were those who stated that heritage played a strong role in their decision to visit Hue (rated 4 and 5 for question 1 ) and had a deep experience (rated 3 and 4 for question 2); Sightseeing heritage tourists were those who indicated that heritage played an important role in their decision to visit (rated 4 and 5 for question 1), however their experiences were fairly shallow (rated 1 and 2 for question 2); Casual heritage tourists were those who identified the mid-point in the motivation scale (rated 3 for question 1) and had shallow experiences (rated 1 and 2 for question 2); Incidental heritage tourists were those who had shallow experiences (rated 1 and 2 for question 2) as well as stated that heritage tourism played little or no role in their decision to visit (rated 1 and 2 for question 1) ; and Serendipitous heritage tourists are those who had a deep experience (rated 3 and 4 for question 2) but indicated that heritage tourism played little or no role in their decision to visit (rated 1, 2, and 3 for question 1).

\section{Findings and discussions}

\section{Hue heritage tourists' profile}

Socio-demographic characteristics 
This is a post-referred version of the paper published in Journal of Heritage Tourism, 9:1, 35-50, DOI:10.1080/1743873X.2013.818677

Among 307 respondents, 24.1\% were Vietnamese and $75.9 \%$ were international tourists. Male (50.3\%) and female (49.7\%) were equally interviewed. Due to the fact that domestic tourists and their international counterparts have different characteristics and the sample sizes of these two groups are not equal, their profiles are mostly interpreted separately. Comparisons are made only occasionally.

Most of the international tourists were European, making up 57.8\% of the total, followed by Australians (25\%), Americans (10.3\%), Asians (4.7\%), Vietnamese overseas $(1.3 \%)$ and Africans (0.9\%). This figure is corresponding to the statistics of international visitor arrivals in Hue. The ages of most international tourists $(83.2 \%)$ were evenly spread across the ranges of 20 to 60 year olds. Meanwhile, interviewed Vietnamese tourists traveling to Hue were somewhat younger than their international counterparts. About 46 out of 72 Vietnamese respondents $(63.9 \%)$ were in the age range between 20 and 40.

Concerning educational level, respondents seemed to be well educated, i.e. $64.6 \%$ of international tourists and $77.8 \%$ of domestic tourists had Bachelor degrees or above. They were mostly employed or self-employed, declared by $87.2 \%$ of domestic tourists and $77.9 \%$ of the international tourists. Their professional careers were generally not connected with culture or heritage, stated by $75.8 \%$ of total respondents.

\section{Tourists' trips in Hue}

Hue was one of the destinations of the tours in Vietnam; therefore, information of the respondents' whole trip was collected. Designed for international tourists, the tours in Vietnam lasted for 14.8 days on average; mostly included 4 to 9 destinations. Meanwhile, the length of the tours for domestic tourists was 5.8 days on average and mostly included 1 to 4 destinations.

Majority of international tourists (65.2\%) and almost all domestic tourists $(91.5 \%)$ visited Hue in the group package tours. The rest of the international $(34.8 \%)$ and domestic tourists $(8.5 \%)$ traveled in the individual package tours. Around half of the domestic tourists (53.4\%) had been in Hue before, while almost all international tourists $(94.3 \%)$ were the first time visitors to Hue. The results also showed that most of the tourists (61.5\%) stayed in Hue for 2 days. Domestic tourists tended to stay slightly longer than international tourists (domestic tourists: mean $=2.5$ days, international tourists: mean=2.1 days, $\mathrm{p}=.014$ ).

When being asked to describe their trips, many of the respondents, i.e. 53\% of the international tourists and $42.5 \%$ of the domestic tourists, considered the trips as cultural or heritage driven. Some tourists also described their trips as ecotourism or nature based trips, stated by $25 \%$ of international tourists and $19.2 \%$ of domestic tourists. Hence, for some of the tourists, their visits to heritage sites in Hue were only optional activities offered to their predominantly nature based trips.

On a five point Likert scale of importance, tourists were asked for the reasons of visiting Hue. Culture/heritage was considered as an important reason to visit the city (mean= 4.36 for international tourists, mean=4.44 for domestic tourists). Ecotourism or nature tourism was also chosen as a reason of visiting Hue, and this reason was more important for domestic tourists (mean=4.0) than for international tourists (mean=3.2). Meanwhile, sun and beach were not an important motive for most tourists' visit, stated by $75 \%$ of international tourists and $70.9 \%$ of the domestic 
tourists. These results are understandable due to the fact that Hue is one of the most famous cultural/heritage destinations in Vietnam and is also well-known for its natural landscape as well as ecotourism. On the contrary, beach tourism is still developing and is less famous than in its neighboring cities. In addition to the above reasons for visiting Hue, simply being included in the tours was also one of the reasons. However, given that Hue was one of the designed destinations of the tours, most of the tourists still considered this was not the single most important reason, since 96 out of 101 respondents, who chose 'It was included in the tour' was important or very important, also chose culture/heritage as an important or very important reason.

Tourists were also asked for their perceptions of Hue city. The majority of the respondents ( $85.5 \%$ of international tourists and $92.2 \%$ of domestic tourists) agreed that 'Hue is a heritage destination with many cultural heritage sites' (mean $=4.3$ for international tourists, mean $=4.6$ for domestic tourists). This explains why heritage was the main reason for coming to Hue and visiting heritage sites was also the main activity in Hue. Hue was also considered as a famous destination in Vietnam, which was agreed by $83.6 \%$ of international tourists and $93.4 \%$ of the domestic tourists. The city, moreover, was thought to offer many things to do and see by many respondents (66.8\% of international tourists and $73.8 \%$ of domestic tourists). It is noticed that domestic tourists were likely to have a more positive image of Hue than international tourists as higher means were given for the statements of "Hue is a heritage destination with many cultural heritage sites" $(\mathrm{p}=.010)$, and "Hue is a famous destination in Vietnam" (p=.003).

During the visits in Hue, almost all tourists (93.2\%) were interested in visiting heritage sites, with a high level of interest (mean=4.54). A large number of tourists $(83 \%)$ also took dragon boat tours and they found the latter as rather interesting (mean=3.59). Other activities, in descending order of number of tourists who have been participating, were shopping, visiting the countryside, going on cyclo tours and going to the beach. It seems these activities were not a priority for most tourists, demonstrated by the mean averages of approximately 3 and more than half of the tourists were 'not interested at all' or 'neither interested nor uninterested' in these activities . Other activities undertaken were the listening to Hue folk songs and court music, enjoying the local cuisine, and walking around the city.

Among the visited heritage sites in Hue, the five most visited sites were the Imperial city (visited by $91.86 \%$ of total respondents), the Thien Mu Pagoda (80.46\%), the Minh Mang tomb (57.98\%), the Tu Duc tomb (65.47\%), and the Khai Dinh tomb (47.23\%). Tourists also seemed to be more interested in those five attractions (means $>4)$ then others (means $<4)(p=.000)$. While there was almost no difference between international tourists and domestic tourists concerning their interests in these five famous attractions, domestic tourists were likely to be more attracted by the less popular heritage sites than international tourists, indicated by the higher mean scores and higher visiting rates. For example, 14\% of international tourists visited Museum of Royal Antiquities and their average level of interest was about 3.06, meanwhile $27 \%$ of domestic tourists visited this site and their average level of interest was 3.85. This finding can be explained by the effects of distance dynamics and first-time/repeated visitation. Geographic distance between the tourist's residential place and relevant destination has been indicated as having a significant influence on tourist behaviour, explained by the cumulative effects of 
cultural distance, time availability, travel motive, costs and many other factors (McKercher, 2008). In a comparative analysis between the domestic and international tourists, Carr (2002) revealed that the domestic tourists were more active than their international counterparts. Besides, studies on first-time and repeat visitors indicated that first-time visitors were more interested in and visited mostly large iconic, popular attractions (Lau \& McKercher, 2004). It is therefore believed that in this study, domestic tourists who were mostly repeat visitors showed higher interest in less popular heritage, as they might have visited the popular attractions during their last visits.

In sum, the results revealed that most of the tourists $(81 \%$ international tourists and $85 \%$ domestic tourists) were satisfied with their visits to Hue.

\section{Tourists' intentions}

Findings showed that domestic tourists were likely to be more interested in learning about Hue cultural heritage than international tourists, i.e. 83.6\% domestic tourists versus $60.7 \%$ international tourists. However, international tourists also showed their interests in learning about Hue cultural heritage (mean=3.77), meaning Hue heritage has the potential to further attract non-local tourists.

Most of the tourists resulted as willing to stay longer in Hue and to see more local culture and heritage. A larger number of domestic tourists (78.4\%) wished to extend their stay in Hue compared to the international tourists (57.6\%). There was still a large number of international tourists $(23 \%)$ who hesitated and showed uncertainty on an extension of their stay, possibly due to the lack of prior information of tourist attractions in Hue. Similar results were found on tourists' revisit intentions. The majority of domestic tourists $(82.4 \%)$ intended to come back again, while almost $60 \%$ of the international tourists had no intention or no clear idea if they want to revisit Hue. This can be explained by the difficulties related to a long-haul trip, the lack of information on the destination, or generally by the low revisiting rate, inherent to the nature of heritage tourism (Ashworth, 2004).

\section{Heritage Tourists' Classification}

\section{Heritage as a reason for the visit and the depth of heritage experiences}

As discussed earlier, the two questions representing two dimensions for classifying heritage tourists were related to the importance of heritage motive and the depth of experience. For the first dimension, heritage was claimed to be an important reason to visit the city by most of the tourists $(86 \%$ of international tourists and $86.7 \%$ of domestic tourists). Heritage was also considered as the most important reason $(m e a n=4.4)$. Others were sun/beach (mean=1.9), ecotourism/nature (mean=3.4), and being included in the tour (mean=3.5).

Table 2. Culture/heritage as a reason to visit Hue city 
This is a post-referred version of the paper published in Journal of Heritage Tourism, 9:1, 35-50, DOI:10.1080/1743873X.2013.818677

\begin{tabular}{|c|c|c|c|c|}
\hline & \multicolumn{2}{|c|}{ International tourists } & \multicolumn{2}{|c|}{ Domestic tourists } \\
\hline & Frequency & Percent & Frequency & Percent \\
\hline Not important at all & 11 & 5.3 & 4 & 5.9 \\
\hline Unimportant & 5 & 2.4 & 0 & 0 \\
\hline Neutral & 13 & 6.3 & 5 & 7.4 \\
\hline Important & 51 & 24.8 & 12 & 17.6 \\
\hline Very important & 126 & 61.2 & 47 & 69.1 \\
\hline Total & 206 & 100.0 & 68 & 100.0 \\
\hline $\begin{array}{l}\text { Mean/Standard } \\
\text { deviation }\end{array}$ & \multicolumn{2}{|c|}{$4.36 / 1.046$} & \multicolumn{2}{|c|}{$4.44 / 1.056$} \\
\hline
\end{tabular}

For the second dimension, international tourists had a fairly shallow heritage experience (mean=1.88). Almost half of the international tourists (46.4\%) claimed that they mostly did sightseeing and photography when they were in Hue. Only $26.9 \%$ of the international tourists stated that the trips provided them with opportunities to learn a lot or to develop deep knowledge related to the Hue cultural heritage. Domestic tourists, meanwhile, seemed to have deeper experiences (mean $=2.54$, $\mathrm{p}=.000$ ). More than half in total had rather deep heritage experiences, but still $27.1 \%$ of the domestic tourists were sightseeing tourists only. The finding that domestic tourists had deeper heritage experiences than international tourists is understandable. It is easier for Vietnamese tourists to understand and learn about the local heritage. More importantly, Vietnamese tourists are likely to consider the Hue cultural heritage as their own personal heritage. Hence, they are highly likely to show more interest and higher motivation to learn more about it.

Table 3. Heritage experiences of tourists

\begin{tabular}{lcccc}
\hline & \multicolumn{2}{c}{ International tourists } & \multicolumn{2}{c}{ Domestic tourists } \\
\cline { 2 - 5 } & Frequency & Percent & Frequency & Percent \\
\hline $\begin{array}{l}\text { 1. Mostly sightseeing/ Photography or } \\
\text { seeing interesting and famous sites }\end{array}$ & 104 & 48.4 & 19 & 27.1 \\
\hline $\begin{array}{l}\text { 2. A chance to learn a little about Hue } \\
\text { Cultural Heritage }\end{array}$ & 53 & 24.7 & 12 & 17.1 \\
\hline $\begin{array}{l}\text { 3. A chance to learn a lot about Hue } \\
\text { Cultural Heritage }\end{array}$ & 39 & 18.1 & 21 & 30.0 \\
\hline
\end{tabular}




\begin{tabular}{lllll}
$\begin{array}{l}\text { 4. A chance to develop a deep } \\
\text { understanding of Hue Cultural } \\
\text { Heritage }\end{array}$ & 19 & 8.8 & 18 & 25.7 \\
\hline Mean/Standard Deviation & $1.88 / 1.004$ & $2.54 / 1.151$ \\
\hline
\end{tabular}

Heritage tourists' categories

Regarding the classification of heritage tourists, 256 out of 307 respondents who answered both questions were found as qualified for classification. Five categories of heritage tourists were found. The vast majority of tourists were either sightseeing tourists or purposeful tourists $(85.9 \%$ international tourists, $87.7 \%$ domestic tourists). The numbers of casual heritage tourists, incidental heritage tourists and serendipitous heritage tourists were rather small; i.e. 27 out of 191 international tourists and 8 out of 65 domestic tourists. The results showed big differences between international and domestic tourists. While the majority of international tourists were sightseeing heritage tourists (63.4\%), the purposeful heritage tourist was the largest group within domestic tourists (47.7\%). Conversely, the second largest group within international tourists was the purposeful tourist $(22.5 \%)$ and within domestic tourists was the sightseeing tourist (40.0\%).

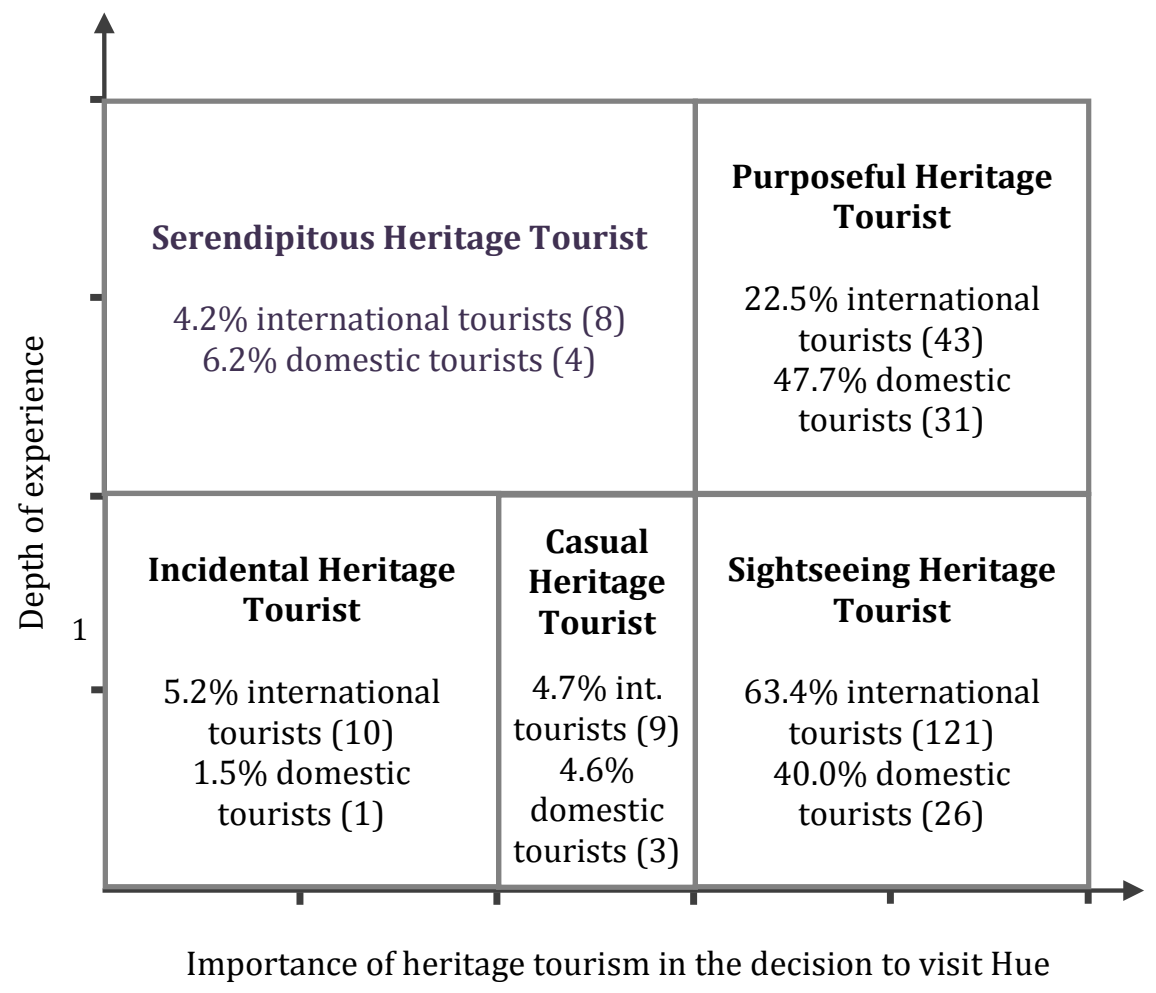

Figure 1. Hue heritage tourists' categories

Due to the small sample size of domestic tourists, statistically significant differences among groups could not be detected. Nevertheless, a different number of destinations during the trip could be observed. Casual tourists and sightseeing tourists seemed to visit more destinations (means of 5.3 and 4.3 respectively) than others types of tourists. 
For international tourists, several differences among groups were found. Casual tourists appeared to have the longest trips in Vietnam (mean=18.33 days). Regarding the length of stay in Hue, purposeful tourists had the longest stays (mean $=2.34$ days). Concerning general information on Hue, as a matter of fact, $70 \%$ of purposeful tourists had read related materials before the visits, while the numbers of the other groups were less than 50\%. Also, purposeful tourists were likely to have a better image of Hue, shown on statements such as 'Hue offers many things to do and see', 'Hue is a famous destination', and 'Hue is a heritage destinations'.

The findings of the serendipitous tourist were considerably interesting. While visiting Hue without heritage visit intentions, they were interested in Hue heritage and have shown to have gained deep heritage experiences. Serendipitous tourists highly agreed that Hue Cultural Heritage sites had raised their knowledge about Hue and Vietnam and that they were satisfied with the trip. They even thought to have insufficient time to learn about the Hue culture heritage, whereas other tourists found their length of stay as appropriate.

In sum, there were a few significant differences among different categories of heritage tourists in terms of tourist demographic characteristics, trip profiles, and travel activities. These findings are comparable to the previous study by McKercher (2002) in detecting a few differences in heritage tourists' demographic characteristics and their trip profiles. McKercher (2002) also claims that these results are supported by other studies which indicated that demographic characteristics and trip profiles were not useful in segmenting cultural/heritage markets. Particularly in this study, the few differences which were detected could also be explained by the population of this study which only included package tourists. The demographic profiles and trip profiles of the respondents were quite similar. Most of the tourists were first time visitors to Vietnam; the tours that they chose, therefore, were the most popular ones and they had almost the same itineraries and travel activities.

\section{Conclusions and implications}

Heritage tourism has been the most important tourism type in Hue city since its early development stage. Hitherto, there are no official statistics for this type of tourism, and published research on the topic of heritage tourism and heritage tourists in Hue has so far been scanty. This paper, therefore, attempted to investigate Hue heritage tourists and their trips' profile, focusing on identifying different categories of heritage tourists using the five cultural typologies of McKercher (2002). This study, however, only examined tourists who were visiting Hue on package tours. The international heritage tourists' profile discovered seemed to be similar to official statistics of international arrivals, indicating almost no difference in sociodemographic profile between heritage tourists and general tourists in Hue. Regarding tourists' trips to Hue, there were significant differences found between international tourists and domestic tourists in terms of the number of visits, their lengths of stay, their perceptions of the tourist destination of Hue, and their interests in less popular heritage sites. Heritage was claimed to be the most important reason to visit the city by most tourists. Nonetheless, their heritage experiences seemed to be rather shallow, especially within the group of international tourists. Using the two dimensions of the importance of heritage for visiting and the depth of heritage experiences, five types of Hue heritage tourists were identified. Among these, 
sightseeing tourists and purposeful tourists were discovered to be dominant. There were, however, significant differences between domestic and international tourists. While the majority of international tourists were sightseeing heritage tourists, almost half of the domestic tourists were purposeful heritage tourists. Only a few significant differences among five categories of heritage tourists were detected in terms of tourist characteristics, and their trips' profile.

This findings echo previous suggestion that tourists' demographic characteristics and their trip profiles are not an effective segmentation means for cultural/heritage tourists (McKercher, 2002). Instead, the importance of heritage motives in the destination choice, and the depth of the heritage experience are believed to be more important elements for identifying heritage tourists as well as for managerial strategies.

The results of this study can be a valuable source for practitioners in order to improve or modify products and services aiming to meet different tourists' demands and needs. This study showed significant differences between international tourists and domestic tourists in terms of interests, perceptions and knowledge towards Hue city and its heritage. It is, therefore, necessary to attract different types of tourists differently with regards to heritage products, especially when considering the interpretation of the latter. For example, brochures and online information that are provided for international tourists and domestic tourists could be designed in different ways. Rather than just the language translation, a difference is suggested also in its content. In particular, Hue's history and the origin of its heritage are able to be explained in-depth for Vietnamese tourists, since they already have general knowledge about the local culture and context. Moreover, it is worthy to design different brochures as added information for different types of tourists with different interests, even if travelling on similar tours. For example, one type of brochure could contain very general information; another has more details about the value and meaning of local heritage. For tourists who have more interest in heritage, this further information can possibly meet their needs and, in the farthest reaches, induce them to return to Hue. In a similar manner, online information could be designed with various types of information to satisfy different groups of tourists.

Finally, as this study utilized secondary data, the investigation of only tourists on package tours is a limitation to the findings, especially related to the differences within the categories. Further research on this topic should include a sample which can represent all tourists visiting Hue in order to obtain more information on the classification of Hue heritage tourists. 
This is a post-referred version of the paper published in Journal of Heritage Tourism, 9:1, 35-50, DOI:10.1080/1743873X.2013.818677

\section{References}

Ashworth, G. J. (2004). The blue - grey transition: heritage in the reinvention of the tourism resort. Retrieved 22 April 2013 from http://www.thebestinheritage.com/files/pdf/the_blue-grey_transition.pdf

Ashworth, G. J., \& Tunbridge, J. E. (1999). Old cities, new pasts: heritage planning in selected cities of Central Europe. GeoJournal, 49(1), 105-116.

Boyd, S. (2001). Cultural and heritage tourism in Canada: Opportunities, principles and challenges. In Timothy D J (ed), The heritage tourist experience: critical essays, Volume two (pp.9-31). England: Ashgate Publishing Ltd.

Finn, M., Elliott-White, M., \& Walton, M. (2000). Tourism and leisure research methods: data collection, analysis and interpretation. Harlow: Pearson Education Ltd.

Garrod, B., \& Fyall, A. (2001). Heritage tourism: A question of definition. Annals of Tourism Management, 28(4), 1049-1052.

Hue Monuments Conservation Centre. (2010). Annual report 2009. Thua Thien Hue: Hue Monuments Conservation Centre.

Hue Monuments Conservation Centre. (2012). Introduction to Hue cultural heritage. Retrieved 2 October 2012 from http://www.hueworldheritage.org.vn/?catid=169

Hue People's Committee. (2012). Online channel of Hue City. Retrieved 2 October 2012 from http://www.huecity.gov.vn/?cat_id=294\&optionid=2\&id=4262

Hue Tourism Office. (2010). Tourism performance of Thua Thien Hue in the period of 1991 to 2009. Thua Thien Hue: Department of Culture, Sport and Tourism.

Huh, J., Uysal, M., \& McCleary, K. (2006). Cultural/heritage destinations: Tourist satisfaction and market segmentation. Journal of Hospitality \& Leisure Marketing, 14(3), 81-99.

ICOMOS, \& WTO. (1993). Cultural tourism - tourism at world heritage sites: the site manager's handbook, $2^{\text {nd }} E d$. Madrid: UN

Isaac, R. (2008). Understanding the behaviour of cultural tourists - Towards a classification of Dutch cultural tourists. The Netherlands: Science Guide.

Kerstetter, D. L., Confer, J. J., \& Graefe, A. R. (2001). An exploration of the specialization concept within the context of heritage tourism. Journal of Travel Research, 39(3), 267-274.

Lau, A. L. S., \& McKercher, R. (2004). Exploration versus acquisition: a comparison of first-time and repeat visitors. Journal of Travel Research, 42(3), 279-285.

McKercher, B. (2002). Towards a classification of cultural tourists. International Journal of Tourism Research, 4, 29-38.

McKercher, B. (2008). The implicit effect of distance on tourist behavior: a comparison of short and long haul pleasure tourists to Hong Kong. Journal of Travel \& Tourism Marketing, 25(3-4), 367-381.

Poria, Y., Butler, R., \& Airey, D. (2001). Clarifying heritage tourism. Annals of Tourism Research, 28(4), 1047-1049. 
This is a post-referred version of the paper published in Journal of Heritage Tourism, 9:1, 35-50, DOI:10.1080/1743873X.2013.818677

Poria, Y., Butler, R., \& Airey, D. (2003). The core of heritage tourism. Annals of Tourism Research, 30(1), 238-254.

Prentice, R. (1993). Motivations of the heritage consumer in the leisure market: an application of the Manning-Haas demand hierarchy. Leisure Sciences, 15, 273-90.

Prentice, R. (1993). Tourism and heritage attractions. London: Rouledge.

Richards, G. (1996). Production and consumption of European cultural tourism. Annals of Tourism Research, 22(2), 261-283.

Richards, G. (2001). The market for cultural attractions. In G. Richards (ed.), Cultural Attractions and European Tourism (pp. 31-53). Wallingford: CAB International.

Shifflet, D. K., \& Associates. (1999). Pennsylvania heritage tourism study. Retrieved 22 April 2013 from http://www.chinaup.com:8080/memberbook/information/6/Pennsylvania $\% 20$ Heritage $\% 20$ TourismStudyfinalreport.pdf

Silberberg, T. (1995). Cultural tourism and business opportunities for museums and heritage sites. Tourism Management, 16(5), 361-365.

Stebbins, R. A. (1996). Cultural tourism as serious leisure. Annals of Tourism Research, 23(4), 948-950.

Swarbrooke, J. (1994). The future of the past: heritage tourism into the 2lst century. In A. V. Seaton (Ed), Tourism: The State of the Art (pp. 222-229). Chichester, UK: John Wiley.

The UNESCO World Heritage Center. (2012). World heritage. Retrieved 22 April 2013from http://whc.unesco.org/en/about

The World Tourism Organization. (2011). Communicating heritage - a handbook for the tourism sector. Madrid: UNWTO.

Hue Tourism Office. (2011). Tourism performance report 2010. Thua Thien Hue: Department of Culture, Sports and Tourism.

Thua Thien Hue Portal. (2012). Hue - The city of heritage. Retrieved 22 April 2013 from http://www1.thuathienhue.gov.vn/Portal_Foreign/Views/Default.aspx

Timothy, D. J. (2011). Cultural heritage and tourism: an introduction. UK: Channel View Publications.

Timothy, D. J. (Ed.). (2007). The heritage tourist experience: critical essays, volume two. England: Ashgate Publishing Ltd.

Timothy, D.J., \& Boyd, S.W. (2003). Heritage tourism. Harlow: Prentice Hall.

Van der Borg, J., Costa, P., \& Gotti, G. (1996). Tourism in European heritage cities. Annals of Tourism Research, 23(2), $306-321$

Vietnam National Administration of Tourism (VNAT). (2012). Report of the 45 year development of tourism industry in Vietnam. Retrieved 22 April 2013 from http://www.vietnamtourism.gov.vn/index.php?cat $=0110 \&$ itemid $=556$ 
This is a post-referred version of the paper published in Journal of Heritage Tourism, 9:1, 35-50, DOI:10.1080/1743873X.2013.818677

Yale, P. (1991). From Tourist attractions to Heritage Tourism. Huntingdon: Elm Publications. 